This item was submitted to Loughborough's Research Repository by the author.

Items in Figshare are protected by copyright, with all rights reserved, unless otherwise indicated.

\title{
Customer orientation of frontline employees and organizational commitment
}

PLEASE CITE THE PUBLISHED VERSION

http://dx.doi.org/10.1080/02642069.2014.886197

PUBLISHER

(C) Taylor \& Francis

VERSION

AM (Accepted Manuscript)

\section{PUBLISHER STATEMENT}

This work is made available according to the conditions of the Creative Commons Attribution-NonCommercialNoDerivatives 4.0 International (CC BY-NC-ND 4.0) licence. Full details of this licence are available at: https://creativecommons.org/licenses/by-nc-nd/4.0/

\section{LICENCE}

CC BY-NC-ND 4.0

\section{REPOSITORY RECORD}

Ifie, Kemefasu. 2019. "Customer Orientation of Frontline Employees and Organizational Commitment". figshare. https://hdl.handle.net/2134/19108. 


\title{
Customer Orientation of Frontline Employees and Organizational Commitment
}

\begin{abstract}
This study investigates the effect of alignment between employee and firm customer orientation on the organizational commitment of frontline service employees. Furthermore, the study examines how the size and nature of the discrepancy between employee customer orientation and firm customer orientation affects organizational commitment.
\end{abstract}

The results suggest that organizational commitment is stronger when employee and firm customer orientation are matched than when they are not. Furthermore, organizational commitment is slightly stronger when employee customer orientation exceeds firm customer orientation than when the reverse is the case. The results suggest that efforts expended by firms in hiring and retaining customer-oriented service workers will be unlikely to yield optimal commitment benefits without simultaneous investments to improve firm-level customer orientation.

Keywords: customer orientation; customer orientation gap; organizational commitment; response surface methodology, polynomial regression 


\section{Introduction}

In the highly competitive service environment today, the role of the frontline service employee is, more than ever, crucial to the success of service firms (Babakus \& Yavas, 2012). It is therefore not surprising that issues around the attitudes and behaviors of frontline service employees continue to interest service scholars. One such issue of interest to researchers is customer orientation. Customer orientation, (hereafter $\mathrm{CO}$ ), has continued to hold the attention of both marketing and service scholars and practitioners for more than four decades because of the belief that $\mathrm{CO}$ is an important resource that should impact positively on important psychological (e.g., commitment, satisfaction) and job (e.g., performance) outcomes of frontline service or boundary-spanning employees (e.g., Brown et al., 2002; Donavan, Brown \& Mowen 2004; Coelho et al., 2010; Babakus \& Yavas, 2012; Rafaeli, Ziklik, \& Doucet, 2008; Chang \& Huang, 2011). As such, CO research generally focuses on the antecedents and/or consequences of individual employee CO (hereafter ECO) or firm CO (hereafter FCO).

Previous research on $\mathrm{CO}$ has conceptualized and modeled the construct in two ways: as a behavior or as an attitude or work value. At the employee level, ECO has been described as a psychological phenomenon antecedent to important job states (Matsuo, 2011; Donavan et al., 2004; Anaza \& Rutherford, 2012), or as frontline employee behaviors that are caused by job states or perceptions of organizational characteristics (e.g. Saxe \& Weitz, 1982; Rozell, Pettijohn \& Parker, 2004). FCO has also been defined as the extent to which a firm engages in activities aimed at providing quality services and satisfaction to the customer; or as 'the set of beliefs 
that puts the customer's interest first" (Deshpande', Farley, \& Webster, 1993: 27). The two different conceptualizations of $\mathrm{CO}$ have thrown up important questions relating to how CO operates to influence workers' psychological and job outcomes; when CO's influence is likely to be most prominent; and its relevance to decisions about selecting and training frontline service employees (e.g., Zablah, et al., 2012; Plouffe, Hulland, \& Wachner 2009).

A recent meta-analytic study on ECO suggests that there is "greater support for...the psychological construal of the construct" (Zablah et al., 2012, pp 21). Therefore, while the mediation perspective has undoubted merit, recent empirical evidence suggests that ECO is best conceptualized as a personality-related attitude, work value or work belief, which exists independently of an organization's CO or other organizational characteristics (Zablah et al., 2012; Matsuo, 2011; Whelan et al., 2010; Grizzle et al., 2009; Stock \& Hoyer, 2005; Brown et al., 2002). In this study, therefore, the psychological construal of ECO is adopted.

A psychological construal of $\mathrm{CO}$ means that ECO and FCO can be treated as independent constructs in empirical studies (e.g.; Grizzle et al. 2009); raising the possibility that ECO and FCO (from the perspective of the employee) may be matched or discrepant. Surprisingly, however, this matching perspective of alignment (Venkatraman, 1989), has received little empirical attention from CO researchers. Therefore, while we know that FCO and ECO independently impact on employee outcomes, we do not know if there are any important consequences associated with either a match or mismatch between ECO and FCO. Furthermore, there is little evidence as to how the type of discrepancy between ECO and FCO affects 
outcomes. These are important omissions because service employees do not operate in a vacuum. Instead, they act within their specific situational contexts, perhaps altering their attitudes and actions based upon perceptions of the organization (Grizzle et al., 2009).

Consequently, this study seeks to provide answers to two research questions. First, what are the interactive effects of ECO and FCO on frontline service employees' work-related psychological outcomes? More specifically, how does the match or mismatch between ECO and FCO impact on service employees' commitment to their organizations? Second, when there is a discrepancy between FCO and ECO, does the direction of the discrepancy matter? The existing literature currently does not distinguish between what we term 'negative' or 'positive' $\mathrm{CO}$ gaps. However, is it possible that the two types of gaps have differential effects on frontline employees' psychological outcomes? For instance, are frontline employees, who perceive themselves as more (or less) customer-oriented than the organizations they work for, more (less) likely to have positive attitudes towards the organization?

In order to answer these questions, we draw upon balance theory (Heider, 1958) and person-environment fit theory (Pervin, 1968; Pervin, 1989; Kristof, 1996) to develop hypotheses predicting the impact of $\mathrm{CO}$ alignment (and misfit) on organizational commitment. We explore organizational commitment because of its critical implications for service worker performance and retention (e.g., Morgan \& Hunt 1994; Zablah et al., 2012). We test our hypotheses with cross-level polynomial regression (a combination of polynomial regression and hierarchical linear modeling, which allows us to test the full surface of the fit relationship while simultaneously controlling 
for non-independence among employees of different branches (Jansen and KristofBrown, 2005).

This study contributes to the literature on frontline service employees and $\mathrm{CO}$ in particular in three ways. First, while previous studies have discussed the CO gap in terms of differences in perceptions between employees and customers (e.g., Steinman et al., 2000), this study is the first, to the researchers knowledge, to define this gap in terms of employee perceptions about themselves and the firm. Second, to the best of the researchers' knowledge, this study is the first to explore the consequences of match/mismatch between employee $\mathrm{CO}$ and firm $\mathrm{CO}$; we conceptualize and empirically test the validity of the $\mathrm{CO}$ alignment- commitment tenet at the personal level. We contribute to knowledge by predicting that organizational commitment will be differentially impacted by the two types of misfit or misalignment (i.e., when ECO exceeds FCO versus when FCO exceeds ECO). While some previous studies have investigated FCO (or related constructs) as a moderator of the influence of ECO on outcomes (e.g., Zablah et al., 2009), these studies, unlike ours, do not account for match or mismatch between the two constructs. Third, by exploring the effects of both the size and nature of the CO gap, this paper provides some needed clarification on how service employees resolve potential internal conflicts that may arise when there is a discrepancy between their own attitudes or values, (in this case $\mathrm{CO}$ ), and the attitudes of the organizations they work for.

From a practical perspective, answers to these questions should provide managers with a better understanding of the psychological processes that drive service employees. An understanding of the nuanced forms of impact of $\mathrm{CO}$ alignment on 
organizational commitment can assist managers in developing strategies for recruiting and managing service employees both at the collective and individual levels. For instance, managers might want to take potential $\mathrm{CO}$ gaps into account when recruiting and deploying service employees. Furthermore, they may be inclined to account for the potential impact of $\mathrm{CO}$ gaps when implementing change initiatives in their organizations.

The balance of this paper is organized as follows. In the next section, we review the relevant literatures and develop our conceptual model and hypotheses. Next, the methodology used in the study is described, after which the empirical results are presented. The article concludes with a discussion of research-related and managerial implications.

\section{Theoretical Background}

\section{Balance Theory}

Balance theory is a motivational theory of attitude change, proposed by Heider (1958), which conceptualizes the consistency motive as a drive toward psychological balance. Balance theory explains an individual's desire to maintain consistency among a triad of linked attitudes. The theory emphasizes that sentiments among actors tend to become consistent with the relations that these individuals have to other objects. According to balance theory, a system of triadic relationships between two persons and an object can be either balanced or unbalanced. In this study, balance theory is applied to a relationship system involving three entities: an employee, the company the employee works for, and the customer as the object within the triad. According to balance theory, this system seeks a balanced state. 
Balance theory is based on the common principles that "the friend of my friend is my friend," "the enemy of my friend is my enemy," "the friend of my enemy is my enemy" and the enemy of my enemy is my friend. There are four possible states when relationships among the three parties are balanced. First, the ideal state occurs when there are strong positive relationships among the three entities (e.g., a friend of my friend is my friend). In this study, the ideal state is when there are positive relationships between the employee-firm (organizational commitment is strong and positive); organization-customer (i.e., FCO is strong and positive), and employeecustomer (i.e., ECO is strong and positive). Balance also occurs in three other situations, i.e., when two of the three bonds are negative (i.e., the friend of my enemy is my enemy, the enemy of my enemy is my friend and the enemy of my friend is my enemy). Imbalance occurs when one of the three relationships is negative and the other two are positive, as it is not cognitively consistent to suggest, for example, that the friend of my enemy is my friend. The argument of balance theory is that, because unbalanced states are sources of stress or psychological dissonance, people strive to minimize them in their relationships, and hence they are less abundant in real social settings.

Using the balance theory logic; when there is a match between the attitudes of an individual (A) and another individual (B) towards an object $O$ (i.e., both are positive or both are negative), then a state of balance occurs when A has a positive attitude towards B. However, if $A$ has a positive attitude towards $B$ and a positive attitude towards $\mathrm{O}$, but $\mathrm{B}$ has a negative attitude towards $\mathrm{O}$, there is a state of imbalance. To achieve a state of balance; A will either have to adjust his sentiment towards B or his 
attitude towards $\mathrm{O}$. Balance theory is thus essentially a psychological theory as the process takes place within the heads of the actors.

Although balance theory has its foundations in the study of close interpersonal relationships, it can also be applied to lower-level relationships, as evident in the examples provided in Heider's classical study (1958: 203-204). The broad applicability of balance theory is illustrated by its use in previous studies in the marketing and management literature. For example, balance theory has been used to explain the employee satisfaction-customer satisfaction link (Homburg \& Stock, 2005) as well service quality (Carson, Carson, Knouse, \& Roe, 1997).

\section{Fit Theory}

The fundamental assumption of fit theory is that outcomes are a function of the fit between individuals and their environments; where good fit generally results in positive outcomes (Kristof, 1996). Two broad types of person-environment fit have been identified in the literature (Kristof, 1996). The first is supplies-values fit which is present when the environment supplies attributes that are desired or valued by a person (Edwards, 1996). This type of fit is supplementary, in the sense that a person and an organization possess matching characteristics (Muchinsky \& Monahan, 1987). The second type of fit is demands-abilities fit, which occurs when an

individual possesses abilities or resources that are required by their environment (Edwards, 1996). This type of fit is complementary because "the weaknesses or needs of the environment are offset by the strength of the individual, and vice-versa" (Muchinsky \& Monahan, 1987,:271). In an organizational context, fit can be assessed in a variety of ways. Accordingly, prior studies have investigated person-group fit 
(Jansen and Kristof-Brown, 2005), person-job fit (Donavan et al., 2004) and personorganization fit (Kristof, 1996). Since there are various types of and different ways of assessing fit, it is useful to specify the type of fit being considered in a study.

In this study, we focus on CO fit from a supplies-value fit perspective. Furthermore, we focus on person-organization fit, which is defined as the interpersonal compatibility between individuals and the organization (Kristof, 1996). In line with the literature, we also distinguish between perceived fit, defined as the judgment or perception of fit, and actual fit, which involves objective comparisons of individual and firm variables (Kristof, 1996). We focus on perceived fit from the perspective of the employee.

\section{Alignment and the Customer Orientation Gap}

Alignment can be conceptualized in terms of mediation or matching (Venkatraman, 1989). The mediation perspective specifies the existence of an intervening mechanism between an antecedent variable and a dependent variable. Conceptually, the mediation perspective implies that $\mathrm{CO}$ is investigated from a process perspective. When applied to the variables in this study, the mediation perspective suggests that an employee's organizational commitment is dependent on ECO. In turn, ECO is influenced by FCO. On the other hand, the matching perspective views alignment as a theoretically defined match between two related variables. For the purpose of this study, the matching perspective of alignment is the focus.

As discussed earlier, it is possible for FCO and ECO to be matched or mismatched. When they are matched, employees might perceive themselves as having a high 
(low) $\mathrm{CO}$ and the organization as also having a high (low) $\mathrm{CO}$. On the other hand, they may be mismatched; here employees may consider themselves as highly customer-oriented while perceiving the organization as low in CO or vice-versa. However, because matching is a theoretically defined concept; there is likely to be, in practice, some discrepancy between ECO and FCO. When the discrepancy is negligible, matching is said to occur and when the discrepancy is not negligible, a mismatch occurs. The discrepancy between ECO and FCO is termed the customer orientation gap. In this study, a positive CO gap exists when FCO exceeds ECO. Conversely, a negative CO gap exists when ECO exceeds FCO.

Previous research indicates that employee's perceptions of organizational characteristics such as FCO are rarely uniform (Martin \& Bush, 2006; Kristof, 1996). Furthermore, research suggests that employees routinely compare their attitudes against their organization's attitudes as a means of determining fit and/or valuecongruence (Kristof, 1996). Drawing upon these studies, it is likely that employees will compare their own CO levels with their organization's CO (Kristof-Brown, Zimmerman, \& Johnson 2005) and, on the basis of this comparison, perceive a positive or negative CO gap. While an employee's evaluation of his or her organization's CO may not always reflect reality, such evaluations are vital determinants of how employees respond (Kristoff, 1996). This is particularly true in the context of boundary-spanners who have to represent their organization to customers (Evans et al., 2002). For example, Caemmerer, \& Wilson, (2011) focus on a related construct of "service orientation discrepancy" where service workers compare their service orientation levels with their organizations'. 


\section{Customer Orientation and Organizational Commitment}

In line with the attitudinal or psychological conceptualization of CO, ECO is defined as the amount of an employee's affect for or against customers (Stock \& Hoyer, 2005) and as "an enduring personal disposition to meet customer needs in an on-thejob context" (Brown et al., 2002, 111). FCO is defined as 'the set of beliefs that puts the customer's interest first" (Deshpande', Farley, \& Webster, 1993: 27). From the perspective of the employee, FCO reflects the $\mathrm{CO}$ of the firm embodied in the attitudes of its leaders.

Organizational commitment is defined as an individual's psychological bond with an organization which has "implications for the decision to continue or discontinue membership in the organization" (Meyer, Allen, and Smith 1993, 539). Organizational commitment thus reflects positive feelings towards the organization.

There is extensive empirical evidence of the link between $\mathrm{CO}$ and organizational commitment. For example, FCO has been shown in previous studies to lead to higher levels of employee commitment (Schneider 1990; Siguaw, Brown, \& Widing, 1994; Jones, Busch, \& Dacin, 2003). The logic for this is that the customer-oriented firm is likely to devote considerable emphasis to meeting customer needs. This emphasis, perceived positively by the employees, influences their commitment to the organization (Jones, Busch, \& Dacin, 2003). At the individual level, ECO has also been shown to influence organizational commitment. Studies such as Zablah et al., (2012) and Donavan et al., (2004) provide empirical evidence of a direct link between ECO and organizational commitment. The authors in these studies draw upon jobdemands resources and fit theories to suggest that the more-customer-oriented an 
employee is, the more the employee will fit into a service organization and thus, the more committed the employee would be to the organization.

\section{Hypotheses Development}

The first two hypotheses presented here pertain to the effect of matching between ECO and FCO on organizational commitment while the third hypothesis concerns how the nature of the $\mathrm{CO}$ gap affects organizational commitment

\section{CO Alignment and Organizational Commitment}

There is an implicit assumption in the literature that the degree of alignment between FCO and ECO should influence how employees' respond to the organization. For example, Evans, et al., (2007, pp 451) argue that "when salespeople perceive a psychological climate of customer orientation, they should feel that the organization, by focusing on the customer, is in line with their own personal goals" (italics included). This statement suggests that employees assess their organizations' CO and compare it with their own $\mathrm{CO}$ goals in order to determine how aligned their goals are with those of the organization (Cable \& Edwards, 2004; Cable \& Judge, 1996). However, empirical examination of the consequences associated with alignment or misalignment is lacking in the literature.

Based on the principles of balance theory explained earlier; when ECO and FCO are matched (both are positive; or both are negative), employee commitment will be positive, in order to maintain a state of balance. However, when FCO is significantly different from ECO (i.e., one is positive and the other negative or vice-versa), a state 
of imbalance occurs if commitment is also positive i.e. strong. To regain a state a balance, the employee can either attempt to match the organization's $\mathrm{CO}$, while maintaining a positive relationship with the organization. On the other hand, the employee may seek to achieve balance by reducing his commitment. We argue that ECO is likely to be more stable and, therefore, more resistant to change than organizational commitment, because ECO is linked to the individual's self-identity. Therefore, situations of misalignment are more likely to result in a negative effect on commitment.

From a supplies-value fit perspective, the relationship between fit and outcomes can be represented by three basic forms: the asymptotic model, the monotonic model, and the optimal model (see Edwards, 1996 for a full review). Our predictions are based on the optimal model. The optimal model suggests that both types of misfit are associated with poorer outcomes than fit. We suggest that a match between the employee and the organization with regards to CO should strengthen the employee's bond with the organization. This is because people have greater intentions to create and maintain relationships with those who are similar to themselves (Zhang and Bloemer, 2008). Insufficient supplies of FCO signify unfulfilled needs, desires, or goals. This creates unpleasantness and weakens affect (Edwards, 1996). On the other hand, excessive FCO interferes with employees' ability to fulfill other needs (Edwards, 1996) and, thus, also weakens affect. Consequently,

$\mathrm{H} 1$ : CO alignment is positively related to organizational commitment, such that employees with matched ECO and FCO will have higher levels of commitment than those with mismatched ECO and FCO. 
Furthermore, because both ECO and FCO have main-effect relationships with commitment (Busch \& Dacin, 2003; Donavan et al., 2004), we propose that commitment will be stronger when perceptions of ECO and FCO are both high than when they are both low. A higher level of ECO suggests that the customer's needs are more salient to the employee. Consequently, when the organization's CO implies a similar importance of customer needs to the organization, the corresponding reaction of the employee to the organization should be stronger. Consequently, the following hypothesis is advanced:

$\mathrm{H} 2$ : When ECO and FCO are matched; organizational commitment will be stronger when both ECO and FCO are high, than when they are both low.

\section{The CO Gap and Organizational Commitment}

While the first two hypotheses argue that commitment is stronger when ECO and FCO are matched than when mismatched, we also suggest that commitment is stronger or weaker depending on the nature of the CO gap. It is important to note that when predicting differential levels of commitment for the two types of misfits, we are investigating circumstances that, consistent with hypotheses 1 and 2, are suggested to be less satisfying than fit.

With respect to supplies-values fit, deficient supplies of a desired value are consistently expected to lead to poorer outcomes than fit (Cable and Edwards, 2004; Edwards, 1996; Kristof, 1996). Excess supplies, however, may or may not lead to poorer outcomes (Edwards, 1996; French et al., 1982). For example, excess supplies 
can be associated with positive psychological reactions when they can be conserved to fulfill preferences on the focal dimension at a later point in time (i.e., conservation), or when they facilitate the fulfillment of preferences on another dimension (i.e., carryover). In contrast, excess supplies are likely to generate less positive reactions when they deplete the resources needed to fulfill one's preferences on the focal dimension at a later point in time (i.e., depletion) or operate as an external distraction and interfere with an individual's ability to meet other needs (i.e., interference). Consequently, the relationship between excess supplies and outcomes depends on which these four processes is operating (Edwards, 1996).

In the case of $\mathrm{CO}$, excess supplies (i.e., too much FCO) cannot be saved for use at a later time; thus, the positive effects of conservation and carryover are unlikely. Instead, the process of interference is most likely to occur here. For example, an employee with deficient $\mathrm{CO}$ levels will have a desired level of engagement with customers. However, such employees are likely to be exposed to constant signals that their $\mathrm{CO}$ levels are not congruent with their organization's $\mathrm{CO}$. We expect that exposure to such feedback creates a constant pressure to try to match the organization's CO. This is likely to weaken the employee's affect for the organization. On the other hand, employees with excess $\mathrm{CO}$ are unlikely to face such situations and therefore will feel less pressure. Consequently, they are likely to be relatively more committed. In line with these explanations, we propose the following hypothesis.

H3: Employees who perceive a negative CO gap will show a higher level of commitment than those who perceive a positive CO gap 


\section{Methodology}

\section{Sample and Data Collection}

Data was collected from frontline service employees of a retail bank. After senior management's consent was secured, customer-contact employees were administered the questionnaire. In total, 525 customer service employees were surveyed across 40 branches. 252 completed surveys were received after three weeks for a response rate of 48 percent. To check for non-response bias, early and the late respondents were compared on demographic and model variables (Armstrong \& Overton, 1977). The t-tests showed no statistically significant differences, which suggests that response bias was not an issue in this study.

The questionnaire included measures of employee customer orientation, firm customer orientation and organizational commitment (see appendix). A global measure of organizational commitment was used. This enabled the authors to capture an overall assessment without either focusing on any one of the several reported dimensions of organizational commitment or including many items. The CO gap was negative (i.e. ECO exceeded FCO) for 124; positive for 103 (i.e. FCO exceeded ECO) and zero for 25 employees respectively.

\section{Measure Assessment}

According to the guidelines suggested by Anderson and Gerbing (1988), we assessed a measurement model before conducting hypotheses testing. Exploratory and confirmatory factor analyses were conducted to test for convergent validity. In arriving at the final set of items for each construct, measures from the initial battery of 
items were deleted, based on the statistical and theoretical grounds. After deleting poorly performing items, the final measurement model achieved excellent fit statistics $(x 2=43.07 ;$ Degree of freedom $=24 ; p$-value $=0.20$, Root Mean Square Error of Approximation $=0.04$; Cumulative fit index $=0.98$, Goodness of fit index $=0.94$ ) and no cross-loadings. This provided evidence of unidimensionality. The validity and reliability statistics are above the recommended thresholds for all constructs. All constructs have an average variance extracted of above 0.7 and composite reliability scores of above 0.7 . For every pair of constructs, average variance extracted exceeds the square of the correlation between the two constructs. Correlations among the variables used in the study are provided in Table 1.

\section{Insert Table 1 here}

Because data was obtained from employees only, and since correlations exceeded 0.5 , the possibility of a common method variance or bias was tested for (Podsakoff et al., 2003). To test for common method bias, a method bias model was estimated (Podsakoff et al., 2003). The results of the test indicate that (a) the addition of the method factor did not cause any of the hypothesised measurement relationships to become non-significant and (b) the hypothesised factor loadings were consistently much higher than the method factor loadings and c) none of the items loaded significantly (t-value>1.645) on the method factor. These results suggest that common method variance is not a serious problem in this study.

\section{Hypothesis testing}


Polynomial regression was utilized to test the hypotheses. Polynomial regression equations allow a researcher to obtain direct tests of theoretical models relevant to the study of alignment (Shanock et al., 2010; Edwards, 1994; Edwards \& Parry, 1993). In developing the variables for the polynomial regression, the procedure outlined by Atwater et al. (2005) was followed. Because employees are nested in branches, there is a possibility for shared variance in the FCO scores. This nonindependence within groups can bias the standard error estimates and lead to the erroneous conclusion that environment variables are significant predictors even if they are not (Bliese, 2002). Therefore, we incorporated the polynomial regression model within hierarchical linear modeling to control for the shared variance in the assessments of FCO. We performed the cross-level polynomial regression with the SAS program using the PROC MIXED command. The resulting set of hierarchical linear modeling equations were specified as follows:

Level 1 equation

$$
Z=\beta 0+\beta 1 P+\beta 2 P^{2}+e
$$

Level 2 equation

$$
\begin{gathered}
\beta 0=\gamma_{00}+\gamma_{01} E+\gamma_{01} E^{2}+\mu 0 \\
\beta 1=\gamma_{10+} \gamma_{11} E+\mu 1 \\
\beta 2=\gamma_{20+} \mu 2
\end{gathered}
$$

Where $\mathrm{Z}$ refers to organizational commitment, $\mathrm{P}$ refers to employee customer orientation and $\mathrm{E}$ refers to firm customer orientation. 


\section{Results}

Table 2 details the results from the polynomial regression.

\section{Insert Table 2 here}

However, simply inspecting the signs and magnitudes of the coefficients in Table 2 reveals little as to the shape of the surface they represent. Response surface methodology (Khuri \& Cornell, 1987; Box \& Draper 1987) provides the basis for describing and testing the required features of surfaces corresponding to quadratic regression equations. This technique has more explanatory potential than difference scores or traditional moderated regression analyses as it can provide a nuanced view of relationships between combinations of two predictor variables and an outcome variable, by showing the results of polynomial regression analyses in a threedimensional graph (Shanock et al., 2010). Rather than examining the regression coefficients, as would be done in a common regression analysis, if the $\mathrm{R}^{2}$ value is significantly different from zero, the results of the polynomial regression are evaluated with regards to four surface test values: a1, a2, a3, and a4 (see Table 3).

\section{Insert Table 3 here}

The slope of the line of fit $(\mathrm{FCO}=\mathrm{ECO})$, as related to organizational commitment, is given by a1. If a1 is negative, the outcome variable decreases as both predictor variables increase. If positive, the outcome variable increases as both predictors increase. Curvature along the line of fit is represented by a2. A significant a2 indicates that agreement in the two predictor variables relates to the outcome in a 
nonlinear fashion. The value a4 represents how the magnitude of discrepancy between FCO and ECO relates to organizational commitment. A significant negative a4 indicates a concave surface, (that is, the outcome variable decreases more sharply as the degree of discrepancy increases). A significant positive a4 indicates a convex surface, (that is, outcomes increase more sharply as the degree of discrepancy increases). Finally, the slope of the line of incongruence, indicating how the direction of the discrepancy (FCO is higher than ECO or vice versa) affects commitment, is represented by a3. A significant negative a3 indicates that the outcome variable is higher when the discrepancy is such that the predictor variable $Y$ (in this case, FCO) is higher than variable $\mathrm{X}$ (ECO) while a significant positive value indicates the opposite.

Figure 1 depicts four basic effects. First, organizational commitment is higher when ECO and FCO are aligned than when they are misaligned. Also, organizational commitment is higher when both FCO and ECO values are both high than when they are both low. Third, the response curve tells us that organizational commitment reduces sharply as the discrepancy between FCO and ECO increases. Fourth, the shape of the curve indicates that the direction of the discrepancy has some impact on organizational commitment. This is because lower levels of commitment occur when FCO is high and ECO is low (towards the left of the graph) than when ECO is high and FCO is low (the right of the graph). However, the test for the direction of discrepancy (a3) is only significant at the 0.1 level. Thus, while the first two hypotheses are fully supported, the third hypothesis is partially supported.

Insert Figure 1 here 


\section{Discussion}

\section{Theoretical Implications}

Previous research has indicated that $\mathrm{CO}$ positively influences organizational commitment. However, a key question of interest is whether an employee's CO will impact on commitment in the same manner in all situations. Our study builds on prior efforts to understand how $\mathrm{CO}$ influences commitment; it however differs from others in that we account for fit and misfit. We view ECO and FCO as intertwined; such that fit or misfit between the two variables impacts on organizational commitment. In essence, the strength of an employee's commitment depends on whether ECO and FCO are matched or mismatched, as well as on the magnitude and direction of the CO gap.

The results suggest that employees, who perceive a match between their $\mathrm{CO}$ and the firm's CO, will display higher levels of commitment than those who perceive a discrepancy. The consequence of a CO gap is, thus, psychological withdrawal in terms of reduced organizational commitment. Furthermore, our findings indicate that commitment is stronger when both variables are high, than when both variables are low. These findings are important because they suggest that, while ECO has a direct influence on organizational commitment; perceptions of compatibility with the environment moderate its impact. Our results are consistent with the findings of Grizzle et al., (2009), who find a moderating impact of service climate on the effect of CO on employee service behaviors. 
The study also provides evidence relating to the differential effects of the two types of CO gaps. We find partial support for the third hypothesis which specifies how the direction of the CO discrepancy affects organizational commitment. Our results provide evidence that there are some predictable differences between the two types of misalignment. Basically, employees with excess $\mathrm{CO}$ are more committed than those with deficient levels of CO. Again, this finding is in line with theory. For instance, findings from previous studies suggest that employees with higher levels of $\mathrm{CO}$ are generally more committed than those with lower levels of CO (Donavan et al., 2004) because they are a better fit for service roles. Employees who perceive a negative CO gap are likely to have higher levels of customer orientation than those who have perceive a positive gap. Hence, they are likely to be more committed. In addition, their higher levels of CO make them less susceptible, than those with lower levels of $\mathrm{CO}$, to interferences from the environment that may weaken their commitment to the organization.

\section{Managerial Implications}

The results of our study generally suggest that organizational commitment is strongest when FCO matches ECO. Furthermore, individuals with excess CO are more committed than those with deficient $\mathrm{CO}$. These results have implications for the management and recruitment of service employees.

The first implication for managers is that, unless new workers CO levels fit with the firms' CO, hiring customer-oriented workers may not automatically lead to a more committed workforce. In essence, efforts expended by firms in hiring and retaining customer-oriented workers will be unlikely to yield optimal commitment benefits 
without simultaneous investments to improve firm-level CO. Because the degree to which ECO can be influenced by external factors such as training is still an unresolved issue among researchers (Zablah et al, 2012), managers need to "mind the gap" when recruiting candidates for service positions or when reassigning employees to new roles. Proper screening procedures should be employed to ensure that only candidates whose $\mathrm{CO}$ best matches the organization's $\mathrm{CO}$ are recruited. This will help to avoid situations where employees, who are deficient in terms of $\mathrm{CO}$, relative to the firm, are hired. However, this screening should also apply to prevent situations where excessively customer oriented employees are recruited. While conventional thinking suggests that the more customer-oriented an employee is, the better it is for the organization, managers, need to be aware that excessive CO (Lam, 2007) may create additional problems apart from a reduced commitment level. For example, it is likely that employees with excessive levels of CO may be more likely to engage in excessive customer-oriented or deviant discretionary behaviors (Lam, 2007); designed to benefit the customer at the expense of the organization. Such behaviors may have implications both for the firm's bottom-line as well as for relational outcomes of customers e.g., customers developing loyalty to the specific service employee rather than through the employee to the organization (see Bove \& Johnson, 2006). The effects of such behaviors are likely to be even more pronounced in situations where the employee and the customer are in contact over a long period. Another implication of this study relates to the implementation of culture change programs. Such initiatives are common in service organizations and generally involve attempts to make the firm more customer-oriented. Clearly, improving FCO should result in a more committed workforce if such improvements help to close the negative CO gap. However, improving FCO, perhaps by changing 
the management of a firm or branch, may lead to a less committed workforce if it increases the CO gap. A less committed workforce creates challenges for the firm in the sense that certain behaviors are likely to be more strongly driven by organizational commitment than by other work attitudes. While employees can be more easily directed in how they serve customers, extra-role behaviors, such as external representation, which have been found to depend heavily on organizational commitment, may suffer when commitment is low (Bettencourt et al., 2005). The implication for managers, therefore, is that changes to FCO may sometimes need to be accompanied by changes at the employee level.

From an employee management perspective, it is important that managers are aware of whether, as well as what types of, CO gaps exist among employees both at the collective as well as at the individual level. As such, it is important to regularly audit employees' CO levels as well as their perceptions of FCO. Such audits can reveal where changes need to be made to FCO. Based on such information, managers can bridge the $\mathrm{CO}$ gap by investing in areas that improve employee perceptions of FCO. The role of communication in managing employee perceptions is also likely to be crucial here. For example, there might be factors affecting an organization in the short term which may influence an employee's perceptions of FCO. However, if employees are kept informed about and involved with such issues, their perceptions of FCO may suffer less in the short run. Consequently, their commitment levels may not be significantly impacted.

\section{Limitations and Future Research}

Naturally, with any research project, it is prudent to consider the study's limitations and areas for future research. The key limitation of this study is the use of cross- 
sectional data from a single service industry. The model should be tested in a different industry to assess if these findings can be generalized.

It may also be worthwhile for future studies to investigate other potential consequences associated with alignment or misalignment of CO. In this study, the authors focus only on organizational commitment as an outcome variable. However, there is a possibility that the effects of matching or mismatch might extend to customer-oriented behaviors of employees. Further research could, therefore, explore the direct consequences of alignment or misalignment for different types of pro-active, reactive and discretionary employee behaviors such as customer oriented boundary spanning behaviors, excessive customer-oriented behaviors, deviant discretion etc. (Lam, 2007). For example, it may be interesting to see if alignment has any implications with regards to employees engaging in negative word of mouth. It may also be worthwhile to explore the consequences associated with the CO gap when team members or other employees are the object of comparison rather than the organization. Future studies may also consider strategies that might assist managers in bridging customer orientation gaps in their organizations. 


\section{References}

Anaza, N., \& Rutherford, B. (2012). How organizational and employee-customer identification, and customer orientation affect job engagement. Journal of Service Management, 23(5), 1-1.

Anderson, J.C., \& Gerbing, D.W. (1988). Structural equation modeling in practice: a review and recommended two-step approach. Psychological Bulletin 103(3), 411423.

Armstrong, J.S., \& Overton, T.S. (1977). Estimating nonresponse bias in mail surveys. Journal of Marketing Research, 14(3), 396-402.

Atwater, L.E., Ostroff, C., Yammarino, F.J., \& Fleenor, J.W. (1998). Self-other agreement: Does it really matter? Personnel Psychology, 51, 577-598.

Babakus, E., \& Yavas, U. (2012). Customer orientation as a buffer against job burnout. The Service Industries Journal, 32(1), 5-16.

Bettencourt, L.A., Brown S.W., \& MacKenzie, S.B. (2005). Customer-oriented boundary-spanning behaviors: Test of a social exchange model of antecedents. Journal of Retailing, 81 (2), 141-57

Bove, L.L., \& Johnson, L.W. (2006). Customer loyalty to one service worker: should it be discouraged? International Journal of Research in Marketing, 23(1), 79-91. 
Bliese, P.D. (2002). Multilevel random coefficient modeling in organizational research: Examples using SAS and S-plus. In F. Drasgow \& N. Schmitt (Eds.), Measuring and analyzing behavior in organizations: advances in measurement and data analysis (pp. 401-445). San Francisco: Jossey-Bass.

Box, G.E.P., \& Draper, N.R. (1987). Empirical model-building and response surfaces. New York: Wiley.

Brown,T.J., Mowen, J.C., Donavan, D.Y., \& Licata, J.W. ( 2002). The customer orientation of service workers: personality trait determinants and effects on self and supervisor performance ratings. Journal of Marketing Research, 39, 110-119.

Cable, D.M., \& Edwards, J.R. (2004). Complementary and supplementary fit: A theoretical and empirical integration. Journal of Applied Psychology, 89(5), 822-834.

Cable, D.M., \& Judge, T. (1996). Person-organization fit, job choice decisions, and organizational entry. Organizational Behavior and Human Decision Processes 67, 294-311.

Caemmerer, B., \& Wilson, A. (2011). An exploration of the service orientation discrepancy phenomenon in a public sector context. The Service Industries Journal, 31(3), 355-370. 
Carson, P.P., Carson, K.D., Knouse, S.B., \& Roe, C.W. (1997). Balance theory applied to service quality: A focus on the organization, provider, and consumer triad. Journal of Business and Psychology, 12(2), 99-120.

Chang, W. J. A., \& Huang, T. C. (2011). Customer orientation as a mediator of the influence of locus of control on job performance. The Service Industries Journal, 31(2), 273-285.

Coelho, F. J., Augusto, M. G., Coelho, A. F., \& Sá, P. M. (2010). Climate perceptions and the customer orientation of frontline service employees. The Service Industries Journal, 30(8), 1343-1357

Cross, M.E., Brashear, T.G., Rigdon, E.E., \& Bellenger, D.N. (2007). Customer orientation and salesperson performance. European Journal of Marketing, 41(7), 821 $-835$

Deshpande', R., Farley, J.U., \& Webster, F.E., Jr. (1993). Corporate culture, customer orientation, and innovativeness in Japanese firms: A quadrad analysis. Journal of Marketing, 57(1), 23-37.

Donavan, D.T., Brown, T.J., \& Mowen, J.C. (2004). Internal benefits of serviceworker customer orientation: Job satisfaction, commitment and organizational citizenship behaviors. Journal of Marketing, 68, 128-146 
Edwards, J. R. (1994). The study of congruence in organizational behavior research: Critique and proposed alternative. Organizational Behavior and Human Decision Processes, 58, 51-100.

Edwards, J. R., \& Parry, M. E. (1993). On the use of polynomial regression equations as an alternative to difference scores in organizational research. Academy of Management Journal, 36, 1577-1613.

Evans, K.R.; Schlacter, J.L.; Schultz, R.J; Gremler, D.D., Pass, M., \& Wolfe, W.G. (2002). Salesperson and sales manager perceptions of salesperson job characteristics and job outcomes: A Perceptual Congruence Approach. Journal of Marketing Theory and Practice, 10(4), 30-44.

Evans, K. R., Landry, T. D., Li, P.C., \& Zou, S. (2007). How sales controls affect jobrelated outcomes: the role of organizational sales-related psychological climate perceptions. Journal of the Academy of Marketing Science, 35(3), 445-459.

French, J. R. P., Jr., Caplan, R. D., \& Harrison, R. V. (1982). The mechanisms of job stress and strain. New York: Wiley

Grizzle, J.W., Zablah, A.R., Brown, T.J., Mowen, J.C., \& Lee, J.M., (2009). Employee customer orientation in context: How the environment moderates the influence of customer orientation on performance outcomes. Journal of Applied Psychology 94(5), 1227-1242. 
Heider, F. (1958). The psychology of interpersonal relations. New York: Wiley.

Homburg, C., \& Stock, R.M. (2005). Exploring the conditions under which salesperson work satisfaction can lead to customer satisfaction. Psychology and Marketing, 22(5), 393-421.

Jansen, K. J., \& Kristof-Brown, A.L. (2005). Marching to the beat of a different drummer: Examining the impact of pacing congruence. Organizational Behavior and Human Decision Processes. 97(2), 93-105. ·

Jones, E., Busch, P., \& Dacin, P. (2003). Firm market orientation and salespersons' customer orientation: Interpersonal and intrapersonal influences on customer service and retention in business-to-business buyer-seller relationships. Journal of Business Research, 56, 323-340.

Khuri, A.. \& Cornell, J.A. (1987). Response Surfaces: Designs and Analyses. New York: Marcel Dekker.

Kristof, A.L. (1996). Person-organization fit: An integrative review of its conceptualizations, measurement, and implications. Personnel Psychology, 49(1), 149.

Kristof-Brown, A.L.; Zimmerman, R.D., \& Johnson, E.C. (2005). Consequences of individuals' fit at work: a meta-analysis of person-job, person-organization, persongroup, and person-supervisor fit. Personnel Psychology, 58(2), 281-243. 
Lages, C.R. (2012). Employees' external representation of their workplace: Key antecedents. Journal of Business Research, 65 (9), 1264-1272

Lam, S.K. (2007). Excessive customer-oriented behaviors in sales. (2007) AMA Winter Educators' Conference Proceedings, 79.

Martin, C.A., \& Bush, A. J. (2006). Psychological climate, empowerment, leadership style, and customer-oriented selling: An analysis of the sales manager-salesperson dyad. Journal of the Academy of Marketing Science, 34(3), 419-438.

Matsuo, M. (2011). The role of sales beliefs in facilitating experiential learning: An empirical study of Japanese salespeople. Psychology and Marketing, 28(4): 309329

Meyer, J.P, Allen, N.J., \& Smith, C. (1993). Commitment to organizations and occupations: extension and test of a three-component conceptualization. Journal of Applied Psychology, 78, 538-551.

Morgan, R.M., \& Hunt, S.D. (1994). The commitment-trust theory of relationship marketing. Journal of Marketing, 58(July), 20-38.

Mowday, R.T., Steers, R.M., \& Porter, L.W. (1979). The measurement of organizational commitment. Journal of Vocational Behavior, 14, 224-247. 
Muchinsky, H.A., \& Monahan, C.J. (1987). What is person-environment congruence? Supplementary versus complementary models of fit. Journal of Vocational Behavior, 31, 268-77.

O'Reilly, C., \& Chatman, J. (1986). Organizational commitment and psychological attachment: The effects of compliance, identification and internalization on prosocial behavior. Journal of Applied Psychology, 71, 492-499.

Pervin, L.A. (1968). Performance and satisfaction as a function of individualenvironment fit. Psychological Bulletin, 69, 56-68.

Pervin, L.A. (1989). Persons, situations, interactions: The history of a controversy and a discussion of theoretical models. Academy of Management Review, 14, 350360.

Plouffe, C.R., Hulland, J., \& Wachner, T. (2009). Customer-directed selling behaviors and performance: A comparison of existing perspectives. Journal of the Academy of Marketing Science, 37(4), 422-39.

Podsakoff, P.M., MacKenzie, S.B., Lee, J.Y., \& Podsakoff, N.P. (2003). Common method biases in behavioral research: A critical review of the literature and recommended remedies. Journal of Applied Psychology, 88, 879-903. 
Rafaeli, A., Ziklik, L., \& Doucet, L. (2008). The impact of call center employees' customer orientation behaviors on service quality. Journal of Service Research, 10(3), 239-255.

Rozell, E.J., Pettijohn, C.E., \& Parker, R.S. (2004). Customer-oriented selling: Exploring the roles of emotional intelligence and organizational commitment. Psychology and Marketing, 21(6), 405-425.

Saxe, R., \& Weitz, B.A. (1982). The SOco scale: A measure of the customer orientation of salespeople. Journal of Marketing Research, 19(3), 343-51.

Schneider, B. (1990). The climate for service: An application of the climate construct. In B. Schneider (Ed.), Organizational Climate (pp. 383-412). San Francisco: JosseyBass.

Shanock, L.R., Baran, B.E., Gentry, W.A., Pattison, S.C., \& Heggestad, E.D. (2010). Polynomial regression with response surface analysis: a powerful approach for examining moderation and overcoming limitations of differences scores. Journal of Business and Psychology, 25, 543-554

Siguaw, J.A., Brown, G., \& Widing, R.E. II (1994). The influence of the market orientation of the firm on sales force behavior and attitudes. Journal of Marketing Research, 31, 106-116. 
Steinman, C., Deshpandé, R., \& Farley, J.U. (2000). Beyond market orientation: when customers and suppliers disagree. Journal of the Academy of Marketing Science, 28, 109-119

Stock, R.M., \& Hoyer, W.D. (2005). An attitude-behavior model of salespeople's customer orientation. Journal of the Academy of Marketing Science, 33, 536-552.

Venkatraman, N. (1989). The concept of fit in strategy research: toward verbal and statistical Correspondence. Academy of Management Review 14(3):423-44.

Whelan, S., Davies, G., Walsh, M., \& Bourke, R. (2010). Corporate branding and customer orientation in the public sector. Journal of Business Research 63(11), $1164-1171$

Zablah, A.R., Franke, G.R., Brown, T.J., \& Bartholomew, D.E. (2012). How and when does customer orientation influence frontline employee job outcomes? A metaanalytic evaluation. Journal of Marketing, 76, 21-40.

Zhang, J., \& Bloemer, J.M.M. (2008). The Impact of Value Congruence on Consumer-Service Brand Relationships. Journal of Service Research 11(2), 161-179 


\section{Appendix}

\section{Measures}

Employee Customer Orientation (Stock and Hoyer, 2004; Brown et al, 2002)

I consider myself to be very customer-oriented.

I enjoy interacting with customers.

I really enjoy serving my customers.

I always have the customers' best interest in mind

I get satisfaction from making my customers happy.

\section{Organizational commitment (Allen and Meyer, 1990)}

I would be very happy to spend the rest of my career with this organization

I feel a strong sense of belonging to my organization

I feel "emotionally attached" to this organization

Organizational Customer Orientation (adapted from Evans, Landry, Li \& Zou, 2007)

My organization is customer-oriented

My organization's business objectives are driven by customer satisfaction

My organization pays close attention to customer service

My organization always has the customers' best interest in mind

My organization's competitive edge is based on understanding customers' needs 
Figure 1: Organizational commitment as predicted by alignment between firm customer orientation and employee customer orientation

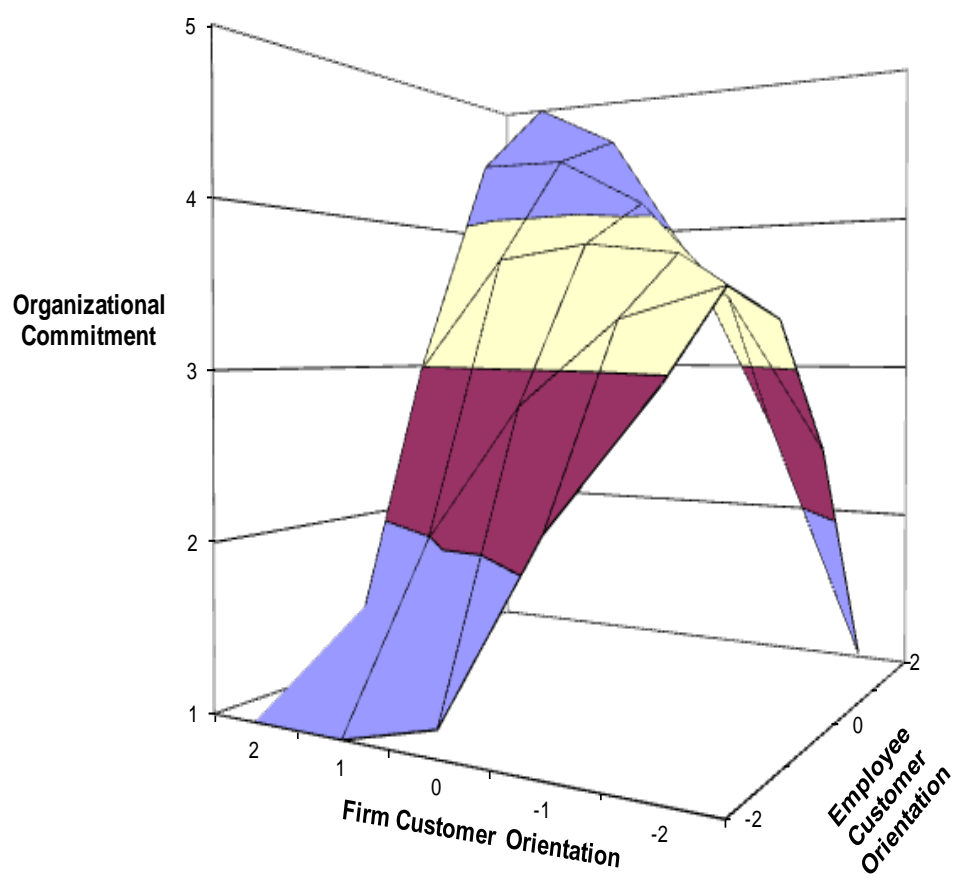

